\title{
Theoretical Determination of Pit Membrane Natural Frequency for Destruction by Resonance Effect
}

\author{
Nasko Terziev, ${ }^{\mathrm{a}, *}$ Geoffrey Daniel, ${ }^{\mathrm{a}}$ and Grigori Torgovnikov ${ }^{\mathrm{b}}$ \\ The low permeability of many wood species causes significant problems \\ during processing. Industrial methods used for increasing wood \\ permeability reduce strength properties, are energy consuming, and are \\ not viable economically. Destruction of pit membranes in wood cell walls \\ can provide an increase in wood permeability without affecting wood \\ strength properties. It can be accomplished using resonance applied to \\ the pit membranes. Theoretical analysis and calculations have been \\ performed to determine pit membrane (torus and margo) natural \\ frequency. Membrane natural frequencies of bordered pits of Norway \\ spruce are in the range of 3 to $11 \mathrm{MHz}$. Water in the pit chamber did not \\ have a significant effect on the resonant frequency of the membrane. The \\ main limitation of the amplitude of membrane fluctuations inside the pit \\ chamber was the width of the chamber. Two methods to initiate resonance \\ frequency for pit membrane destruction have been suggested, namely, \\ alternating electric field application and microwave energy pulsation.
}

Keywords: Bordered pits; Margo; Microwave treatment; Resonance frequency; Torus; Wood permeability

Contact information: a: Department of Forest Biomaterials and Technology/Wood Science, Swedish

University of Agricultural Sciences Box 7008, Uppsala, Sweden; b: School of Ecosystem and Forest

Science, University of Melbourne, 4 Water Street, Creswick, Victoria 3363, Australia;

*Corresponding author: nasko.terziev@slu.se

\section{INTRODUCTION}

Many wood species have low permeability, which can cause problems during the processing of the wood material. Examples of problems are penetration of chemicals during processing of chemical pulp, long and expensive drying times, material loss after timber drying, and difficulties of timber impregnation with preservatives. Therefore, it is essential for the pulp- and timber industry to find new methods that can provide an increase of wood permeability without negative effects on the morphology and strength properties of wood.

Some methods for increasing wood permeability such as steam explosion (Mason 1926) and microwave (MW) wood modification (Torgovnikov and Vinden 2009) have been tested. Intensive MW power applied to wood generates steam pressure within wood cells. Under high internal pressure, pit membranes in wood cell walls and tyloses in vessels and ray parenchyma cells rupture to form pathways for easy transportation of liquids and vapor into the wood. However, the method has significant shortcomings, e.g., reduction of wood strength properties, high-energy consumption, and microwave equipment cost. In comparison, steam explosion increases wood permeability but ruptures the entire wood structure, thereby significantly reducing strength properties along with high-energy consumption. Therefore, these methods have limited applications in industry, particularly in solid wood processing.

An interesting technological question is whether tracheid pit membranes in softwoods can be ruptured selectively to allow a significant increase in wood permeability 
without destruction of other wood structural elements, i.e., without negative effects on the wood physical and mechanical properties. The range of pit membrane (torus and margo) natural oscillation frequencies can be calculated, making possible the application of resonance forces to destroy pit membranes. The aim of the present theoretical study is to determine the range of pit membrane natural oscillation frequencies of softwoods. As an example, the study focuses on Norway spruce (Picea abies (L.) Karst.) that has low permeability but is highly used in the pulp and paper and saw mill industries. Table 1 contains abbreviations used in this paper.

Table 1. Symbols and Abbreviations

\begin{tabular}{|c|c|c|}
\hline Symbol & Definition & Unit \\
\hline$A_{\mathrm{c}}$ & Maximum amplitude of membrane vibration & $\mu \mathrm{m}$ \\
\hline$C_{\mathrm{s}}$ & Sound velocity & $\mathrm{cm} / \mathrm{s}$ \\
\hline$D$ & Diameter of margo & $\mu \mathrm{m}$ \\
\hline d & Diameter of torus & $\mu \mathrm{m}$ \\
\hline$d_{\mathrm{a}}$ & Aperture diameter & $\mu \mathrm{m}$ \\
\hline$E$ & Young's modulus & dyn/cm ${ }^{2}$ \\
\hline$\overline{F_{\mathrm{c}}}$ & Force of resistance to movement in water & dyn \\
\hline$F_{\mathrm{e}}$ & Elastic force per unit length & dyn/cm \\
\hline$F_{\mathrm{i}}$ & Inertial force per unit length & dyn/cm \\
\hline$F_{\mathrm{p}}$ & Breaking force & dyn \\
\hline$f$ & Frequency & $\mathrm{Hz}$ \\
\hline$f_{0}$ & Resonance frequency & $\mathrm{Hz}$ \\
\hline$H$ & Torus thickness & $\mu \mathrm{m}$ \\
\hline$H_{c}$ & Chamber width & $\mu \mathrm{m}$ \\
\hline$h$ & Margo thickness & $\mu \mathrm{m}$ \\
\hline$h_{\mathrm{c}}$ & In the model: Margo thickness & $\mu \mathrm{m}$ \\
\hline$h_{\mathrm{m}}$ & In the model: Membrane thickness & $\mu \mathrm{m}$ \\
\hline 1 & Moment of inertia of the cross section of membrane & $\mathrm{m}^{4}$ \\
\hline$k$ & Wave vector & $\mathrm{cm}^{-1}$ \\
\hline$i$ & Imaginary part & \\
\hline$r$ & Radius & $\mu \mathrm{m}$ \\
\hline$S$ & Membrane cross-sectional area in perpendicular plane & $\mu \mathrm{m}^{2}$ \\
\hline$S_{c}$ & Pit chamber cross-sectional area & $\mu \mathrm{m}^{2}$ \\
\hline So & Area of the sum of openings in margo and aperture & $\mu \mathrm{m}^{2}$ \\
\hline$\partial=S_{c} / S_{0}$ & $\begin{array}{l}\text { Ratio of the area of the passage of the pit chamber to the sum } \\
\text { of the area of the passage in margo and aperture }\end{array}$ & \\
\hline V & Velocity & $\mathrm{cm} / \mathrm{s}$ \\
\hline$z V_{1}$ & Average membrane velocity & $\mathrm{cm} / \mathrm{s}$ \\
\hline$z$ & Coordinate axis & \\
\hline Y & Excitation frequency & $\mathrm{Hz}$ \\
\hline$\varepsilon$ & Relative elongation (tensile deformation) & $\mu \mathrm{m}$ \\
\hline$\eta$ & Dynamic viscosity & $\mathrm{g} / \mathrm{cm} \mathrm{s}$ \\
\hline$\lambda$ & Wavelength & $\mathrm{nm}$ \\
\hline$v$ & Kinematic viscosity & $\mathrm{cm}^{2} / \mathrm{s}$ \\
\hline$\rho$ & Cellulose density & $\mathrm{g} / \mathrm{cm}^{3}$ \\
\hline$\rho_{\mathrm{w}}$ & Water density & $\mathrm{g} / \mathrm{cm}^{3}$ \\
\hline$\sigma_{t}$ & Tensile strength & dyn/ $/ \mathrm{cm}^{2}$ \\
\hline$\omega=2 \pi f$ & Angular (circular) frequency & $\mathrm{rad} / \mathrm{sec}$ \\
\hline$\omega_{0}$ & Imaginary frequency & $\mathrm{Hz}$ \\
\hline
\end{tabular}




\section{EXPERIMENTAL}

\section{Frequency Calculation of Pit Membrane Resonance}

Many publications have discussed the morphology and functions of simple, bordered (Fig. 1), and half-bordered pits in conifers.

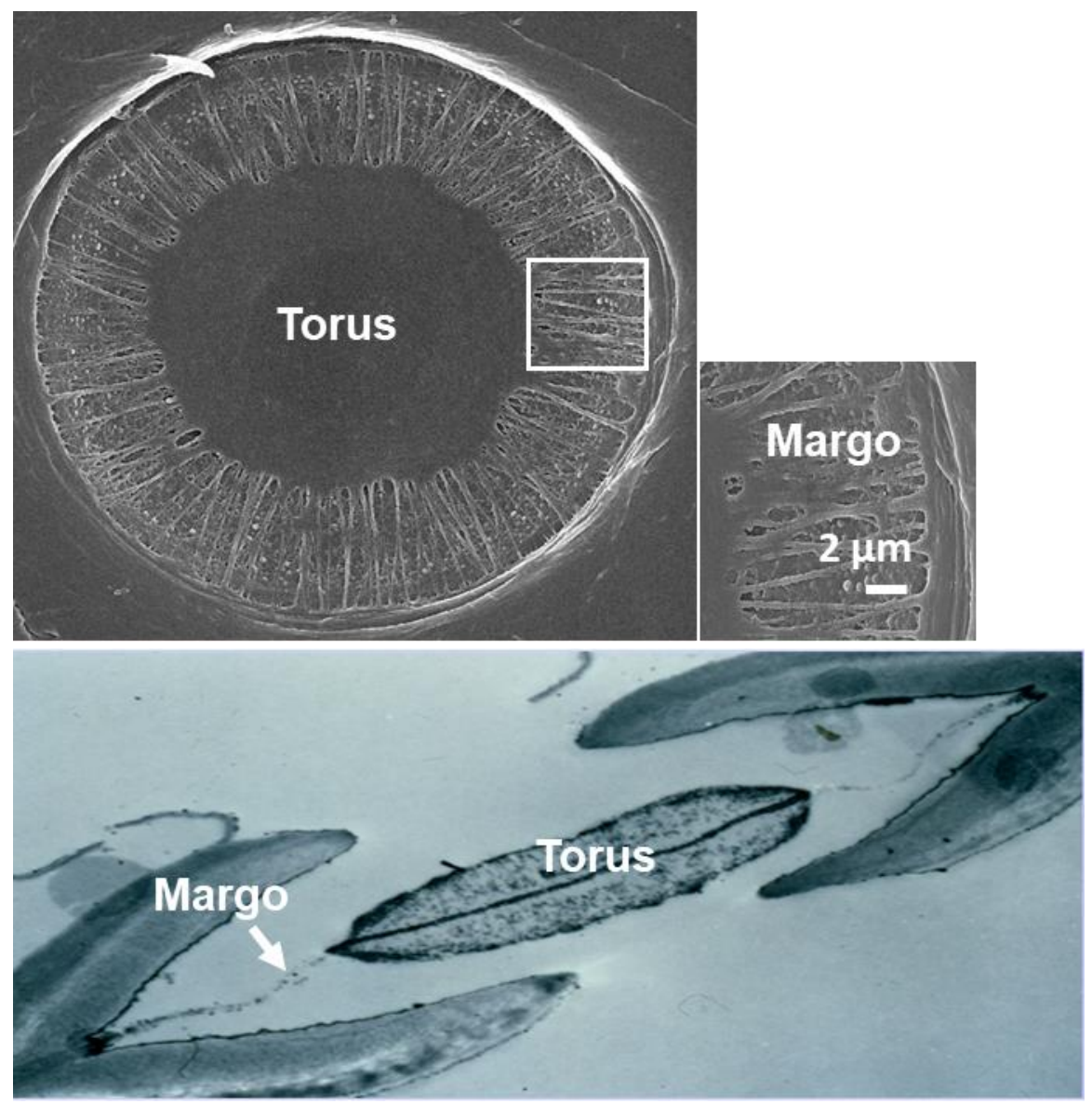

Fig. 1. Scanning and transmission electron micrographs of aspirated (above) and unaspirated bordered pit (underneath)

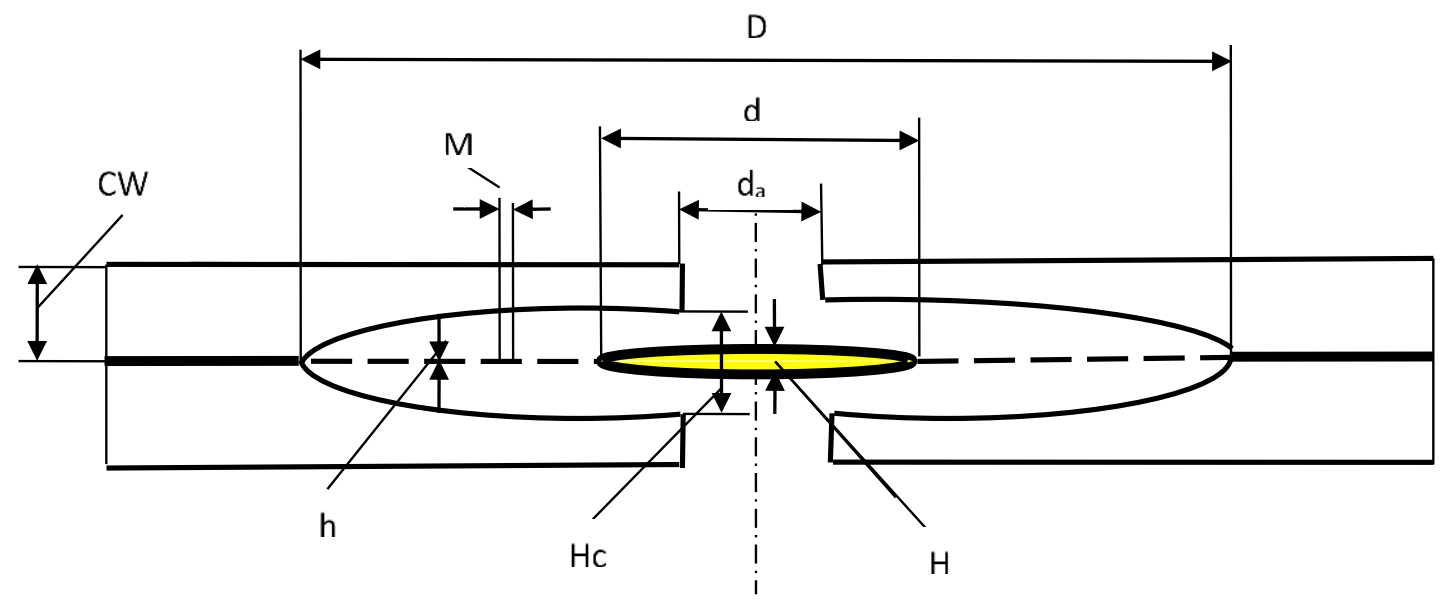

Fig. 2. Specific dimensions of a bordered pit described further in Table 2 
Table 2. Data on Bordered Pit Dimensions $(\mu \mathrm{m})$ of Norway Spruce. Cell Wall Substance Density $-1.53 \mathrm{~g} / \mathrm{cm}^{3}$, Density of Cellulose $-1.55 \mathrm{~g} / \mathrm{cm}^{3}$

\begin{tabular}{|c|c|c|c|}
\hline & Minimum & Maximum & Average \\
\hline \multicolumn{4}{|c|}{ Cell wall thickness CW } \\
\hline Earlywood & 2.8 & 3.5 & 3.2 \\
\hline Latewood & 3.2 & 5.0 & 4.1 \\
\hline \multicolumn{4}{|c|}{ Pit chamber diameter D } \\
\hline Earlywood & 10 & 25 & 17.5 \\
\hline Latewood & 10 & 15 & 12.5 \\
\hline \multicolumn{4}{|c|}{ Pit chamber aperture $d_{a}$} \\
\hline Earlywood & 1.4 & 5.0 & 3.2 \\
\hline Latewood & 1.4 & 5.0 & 3.2 \\
\hline \multicolumn{4}{|c|}{$\begin{array}{l}\text { Pit chamber width } \mathrm{Hc} \text { in earlywood is adopted as cell wall } \\
\text { thickness } \times 2 \text {; for latewood it is equal to the cell wall thickness }\end{array}$} \\
\hline Earlywood & $2.8 \times 2=5.6$ & $3.5 \times 2=7.0$ & 6.3 \\
\hline Latewood & 3.2 & 5.0 & 4.1 \\
\hline \multicolumn{4}{|c|}{$\begin{array}{l}\text { Torus diameter } \mathrm{d} \text { (twice as large as aperture diameter } \mathrm{d}_{\mathrm{a}} ; \\
\left(\text { Siau, 1984), i.e. } \mathrm{d}=2 \mathrm{~d}_{\mathrm{a}}\right.\end{array}$} \\
\hline Earlywood & 2.8 & 10 & 6.4 \\
\hline Latewood & 2.8 & 10 & 6.4 \\
\hline \multicolumn{4}{|c|}{ Torus thickness $\mathrm{H}$} \\
\hline Earlywood & 0.2 & 1.0 & 0.6 \\
\hline Latewood & 0.3 & 1.2 & 0.75 \\
\hline \multicolumn{4}{|c|}{ Margo diameter $\mathrm{D}$} \\
\hline Earlywood & 10 & 25 & 17.5 \\
\hline Latewood & 10 & 15 & 12.5 \\
\hline \multicolumn{4}{|c|}{ Margo thickness $\mathrm{h}$} \\
\hline Earlywood & 0.1 & 0.5 & 0.2 \\
\hline Latewood & 0.1 & 0.5 & 0.2 \\
\hline \multicolumn{4}{|c|}{ Openings in margo, $\mathrm{M}$} \\
\hline Early wood & & & 0.25 \\
\hline Late wood & & & 0.25 \\
\hline
\end{tabular}

Saren et al. (2001), Zimmermann (1983), Siau (1984), Stamm (1964), Brändström (2001), Rosner et al. (2007), and Mayr et al. (2003) are the most relevant when describing the dimensions of Norway spruce bordered pits; the above literature findings have been compiled in Table 2 and illustrated in Fig. 2.

\section{Pit Membrane Model}

By definition, the torus is a continuous medium and presented as a cylinder with diameter $d$ and thickness $H$ (Fig. 3). For simplification, it is presumed that the microfibrillar strands of the margo are also a continuous medium.

Because the microfibrillar strands of the margo are thinner than the torus, they are expressed as one thinner cylinder with external and internal diameters $D$ and $d$ and a thickness $h_{\mathfrak{c}}(r)$, which decreases along the radius (Fig. 3). Thickness decrease is justified by the fact that the constant number of strands originating from the torus reach the periphery of the pit chamber with larger diameter than torus. Thus, the relationship between $h_{c}(r)$ and the radius $D / 2$ is presumed linear.

$$
h_{c}(r)=h\left(1-\frac{2\left(r-\frac{d}{2}\right)}{D}\right)
$$




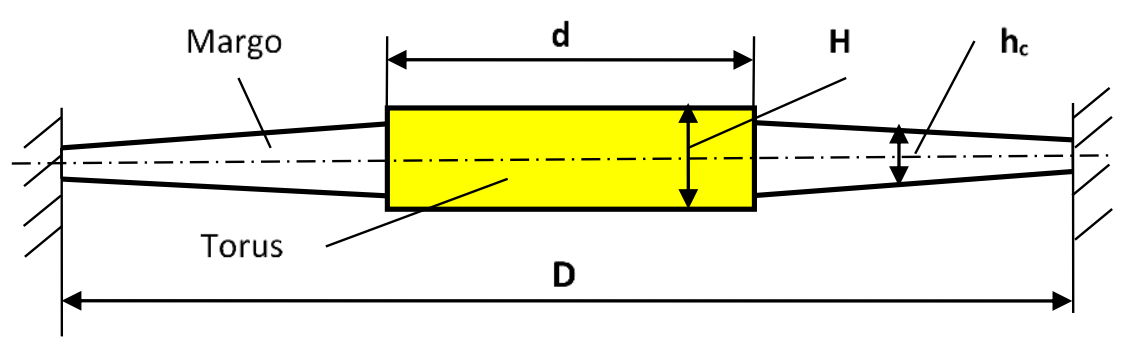

Fig. 3. Model of a pit membrane consisting of torus and margo

The model of torus and margo (called membrane), consists of 2 cylinders forming one entity with a thickness $h_{m}=H$ when $r<\frac{d}{2}$ or $h_{m}=h_{c}(r)$ when $\frac{d}{2}<r<\frac{D}{2}$. It should be noted that the sharp change in the thickness of the membrane at the junction of the two cylinders will affect the shape of the membrane when deflected, i.e., it will be distorted. A tangent to the midline of the membrane will experience a jump at the junction when moving from one cylinder to another. Practically the jump will not affect the frequency of natural oscillations, as a system with a continuous mass distribution is not sensitive to local perturbations.

For quantitative calculations of membrane fluctuation characteristics caused by bending, the moment of inertia of the membrane related to its midline (dashed line in Fig. 3 ) and the area of this section are required. The moment of inertia of the membrane cross section in the plane of Fig. 3 related to its midline, by the definition of Landau and Lifshitz (1986), is shown in Eq. 2.

$$
I=\int_{-d / 2}^{d / 2} d r \int_{-H / 2}^{H / 2} z^{2} d z+2 \int_{d / 2}^{D / 2} d r \int_{-h\left(1-2\left(r-\frac{d}{2}\right)\right) / 2}^{h\left(1-2\left(r-\frac{d}{2}\right)\right) / 2} z^{2} d z
$$

The first integral is the moment of inertia of torus (inner cylinder) and the second integral the moment of inertia of margo (outer cylinder), which are shown within the limits of integration. Computing the integrals results in Eq. 3.

$$
I=\frac{H^{3} d}{12}+h^{3} D\left(1+\left(\frac{d}{D}\right)^{4}\right) / 48
$$

The value $\left(\frac{d}{D}\right)^{4} \approx \frac{1}{50}$, i.e. it is negligible; thus, the moment of inertia is given in Eq. 4 .

$$
I=\frac{H^{3} d}{12}+\frac{h^{3} D}{48}
$$

The membrane cross-sectional area is the sum of the area of torus (the rectangle $H \times d$ ), and the area of the isosceles trapezoid where the two legs are of equal length and described by formula (1). The area is calculated as shown in Eq. 5.

$$
S=H d+h\left(1+\frac{d}{D}\right)(D-d) / 2
$$

Thus, the preparatory operations are completed. For a better understanding of the degree of influence of various factors on the frequency of natural fluctuations of membrane, three examples are considered. 


\section{Membrane Fluctuations in Air}

Neglecting the presence of pit chamber and water and presume that the membrane is in air. An equation describing the vibrations of the membrane can be derived (Fig. 4).

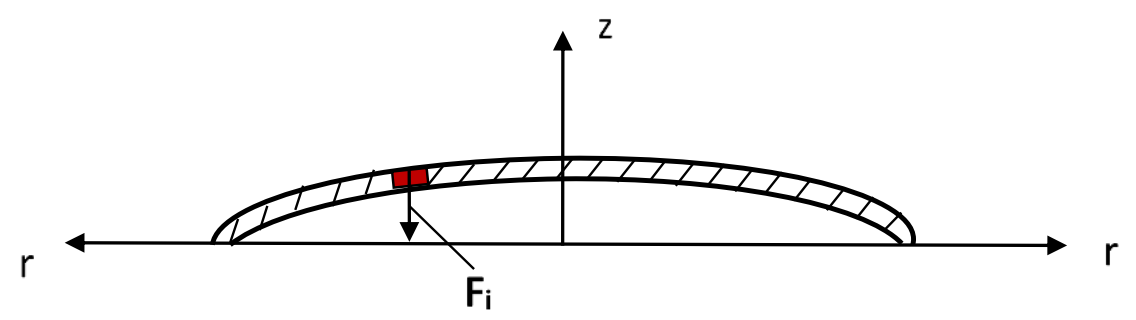

Fig. 4. Membrane model for calculations

When the membrane is deflected, the inertial force $F_{i}$ per unit of its length is given by Eq. 6 ,

$$
F_{i}=-\rho S z_{t}^{\prime \prime}
$$

where $\mathrm{zt}^{\prime \prime}$ is the partial derivative of $2^{\mathrm{d}}$ order with regard to time. The elastic force caused by the deflection of the membrane per unit length is determined by the formula of Landau and Lifshitz (1986) (Eq. 7),

$$
F_{i}=E\left(I z_{r}{ }^{\prime \prime}\right)^{\prime \prime}
$$

where $z_{r}{ }^{\prime \prime}$ is the partial derivative with regard to the $2^{\mathrm{d}}$ order radial coordinate and $E$ is the Young's modulus. Taking the derivative of $\left(I z_{r}{ }^{\prime \prime}\right)$ results in Eq. 8,

$$
F_{e}=E I^{\prime \prime} z_{r}{ }^{\prime \prime}+E I z_{r}{ }^{\prime \prime \prime \prime}
$$

where $z_{r}{ }^{\prime \prime \prime \prime}$ is the partial derivative with regard to the $4^{\text {th }}$ order radial coordinate. For the moment of inertia in Eq. 4, the first term on the right-hand side is zero, as $I$ is a constant.

Equating the inertial and elastic forces (Eq. 6) and (Eq. 8) to each other, a $4^{\text {th }}$ degree partial differential equation is obtained.

$$
E I z_{r}^{\prime \prime \prime \prime}+\rho S z_{t}^{\prime \prime}=0
$$

Substituting the moment of inertia of section (Eq. 4), sectional area (Eq. 5) in (Eq. 9) and reducing it by $H d$, Eq. 10 is obtained.

$$
\frac{E H^{2}\left(1+\frac{h^{3} D}{4 H^{3} d}\right)}{12 \rho z_{r}^{\prime \prime \prime}}+\left(1+\frac{\left(\frac{D}{d}-\frac{d}{D}\right) h}{2 H}\right) z_{t}^{\prime \prime}=0
$$

To find the vibration frequency in Eq. 10, its dispersion equation should be used to find the relationship $\omega=f(k)$. Thus, Eq. 10 was substituted in the form of a wave perturbation $z=z_{0} \exp (-i(\omega t-k r))$, whose partial derivatives are:

$$
z_{t}^{\prime \prime}=-z_{0} \omega^{2} \exp (-i(\omega t-k r)) \text { and } z_{r}{ }^{\prime \prime \prime}=z_{0} k^{4} \exp (-i(\omega t-k r))
$$

Substituting the derivatives (Eq. 11) into Eq. 10, $\omega=f(k)$ is obtained.

$$
\left.\left.\omega=\left(\sqrt{H k^{2}\left(\frac{E}{12 \rho}\right)}\right) \sqrt{((1}+h^{3} D / 4 H^{3} d\right) /\left(1+\left(\frac{D}{d}-\frac{d}{D}\right) h / 2 H\right)\right)
$$


Equation 12 is a form that is convenient for analysis. It is desirable to apply low frequencies or long wavelengths for an effective impact on the membrane to rupture it. The entire system should be effected; the membrane takes the form of half the period of a sinusoid during deflection as shown in Fig. 4. The lowest frequency is obtained when half the wavelength $\lambda$ is in the system, i.e. $\lambda=2 D$ or $k=\pi / D$, which corresponds to the main resonance. Having completed these procedures, the main resonant frequency was obtained in Eq. 13,

$$
f_{0}=\pi A H c_{s} / 4 D^{2} \sqrt{3}
$$

where:

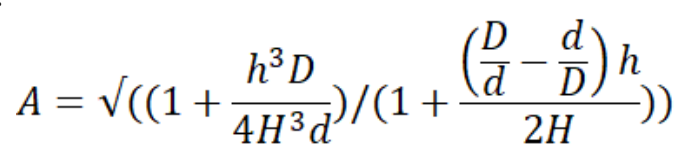

The main resonant frequencies for the data in Table 2 and velocity $c_{s}=4.9 \times 10^{5}$ $\mathrm{cm} / \mathrm{s}$, calculated by assuming $E=3.7 \times 10^{3} \mathrm{~kg} / \mathrm{mm}^{2}=3.7 \times 10^{11} \mathrm{dyn} / \mathrm{cm}^{2}$ and $\rho=1.55$ $\mathrm{g} / \mathrm{cm}^{3}$ (Sjöström 1993) are presented in Table 3. The speed of sound in a solid body with a small Poisson's ratio is $c_{s}=\sqrt{\frac{E}{\rho}}$ (Landau and Lifshitz 1986).

Table 3. Destructive Resonant Frequencies for Early- and Latewood Membranes

\begin{tabular}{|l|c|c|}
\hline \multirow{2}{*}{} & \multicolumn{2}{|c|}{ Resonant Frequency $(\mathrm{MHz})$} \\
\cline { 2 - 3 } & Earlywood & Latewood \\
\hline Minimum-size Membranes & 3.45 & 5.4 \\
\hline Average-size Membranes & 3.4 & 8.9 \\
\hline Maximum-size Membranes & 2.8 & 10.9 \\
\hline
\end{tabular}

Analysis of the resonant frequencies shows that they are always larger in latewood due to an increase in membrane stiffness. Latewood torus has greater thickness $(0.3 \mu \mathrm{m}$ versus $0.2 \mu \mathrm{m}$ in earlywood, Table 2). The stiffness is higher, and it is more difficult to bend, which explains the minimum values. For the maximum values, latewood has a membrane diameter of $15 \mu \mathrm{m}$, while earlywood has $25 \mu \mathrm{m}$ (Table 2). The membrane is shorter, the stiffness is higher, and, as above, it is more difficult to bend. The multidirectional change in the main resonance frequency of the early- and latewood pit membranes in the transition from minimum to maximum values is also interesting: in earlywood, the frequency decreases, while in latewood it increases. This is because the ratio of the maximum and minimum diameters of the margo in earlywood is 2.5 , but only 1.5 in latewood; the ratio of the maximum and minimum torus thickness in the early- and latewood is 5 and 4 respectively (see Table 2). Therefore, the frequency in the earlywood changes as $5 / 2.5^{2}$, i.e. 0.8 times $<1$, and in the latewood $4 / 1.5^{2}=1.78$ times $>1$.

\section{Membrane Fluctuations in Water}

The effect of water on membrane fluctuations is considered, disregarding the pit chamber. During fluctuations in water, a viscosity force will act on the membrane, inhibiting its movement. The viscosity force should be introduced in Eq. 9. The formula of the viscosity force depends on the regime of body motion in the fluid, which is determined by Reynolds number; $R e=\frac{\rho \mathrm{aV}}{\eta}=\mathrm{aV} / \mathrm{v}$, where $a$ is a characteristic dimension. 
In this case, the characteristic dimension is $a=d$, because, as shown in the next section, water flows through the margo quite freely and the main resistance is caused by the torus. The membrane velocity estimate is obtained from analysis of membrane vibrations found in the previous section.

During the oscillation period $1 / f_{0} \approx 0.3 \mu \mathrm{s}$, the membrane passes a distance equal to two- chamber widths $\approx 10 \mu \mathrm{m}$ (in one period, i.e., forward and back); therefore, its average speed is $V_{1} \approx 3000 \mathrm{~cm} / \mathrm{s}$. The dynamic viscosity of water is $\eta=10^{-2} \mathrm{~g} / \mathrm{cm} \mathrm{s}$. Substituting all values produces $R e=d \rho V_{1} / \eta \approx 100$. Thus, despite the high speed, the Reynolds number is small since the dimensions of the "moving object" are very small $\approx 3$ to $5 \mu \mathrm{m}$. The small Reynolds number shows that the flow regime is practically laminar and the relationship of the viscosity force and the velocity is linear; thus, the force formula is $F_{c} \approx 40 \eta d V$ (Ebert 1976). By introducing the force per unit length of the membrane, equal to the force $F_{c} \approx 40 \eta d V$ and by dividing by the membrane diameter $D$ and considering $V=z_{t}{ }^{\prime}$ in Eq. 9 as the force per unit length of the membrane $\frac{F}{D}$, Eq. 14 is obtained.

$$
E I z_{r}^{\prime \prime \prime \prime}+40 \eta\left(\frac{d}{D}\right) z_{t}^{\prime}+\rho S z_{t}^{\prime \prime}=0
$$

Transforming Eq. 14 further produces Eq. 15.

$$
E I+40 v d / D S z_{t}^{\prime}+z_{t}^{\prime \prime}=0
$$

Transition to the dispersion equation is done in the same way as in the previous section (as in Eq. 11). After substituting $z=z_{0} \exp (-i(\omega t-k r))$, a new dispersion equation is obtained.

$$
\frac{E I}{\rho S k^{4}}-\frac{i 40 v d}{\left(D S \omega-\omega^{2}\right)}=0
$$

Due to the existence of an imaginary quantity in Eq. 16, the frequency solution in the form $\omega=\omega_{0}+i \gamma$ is required, where $\omega_{0}$ is the real part of the frequency and $\gamma$ is the imaginary term presenting the attenuation. Substituting $\omega$ into Eq. 16,

$$
\begin{aligned}
& \omega_{0}=\sqrt{ }\left(\left(\frac{E I}{\rho S}\right) k^{4}-400\left((v d)^{2} /(D S)^{2}\right)\right. \\
& \gamma=-20 v d / D S
\end{aligned}
$$

The first term under the root in Eq. 17 is the frequency defined by Eqs. 12 and 13. The second term is a newly added item, considering the viscosity that leads to a decrease in frequency. Evaluating its effect on the frequency found in the previous section, and considering that $k=\pi / D$ and $\pi^{2} \approx 10$, the ratio of the additive to the frequency is shown below.

$$
4 d D^{3} v^{2} / I S c_{S}^{2}
$$

An example is the calculations of the characteristics of the most "influential" case: earlywood with minimum dimensions $D=10 \mu \mathrm{m}, H=0.2 \mu \mathrm{m}, h=0.1 \mu \mathrm{m}, d=2.8 \mu \mathrm{m}$ (Table 2), $v=10^{-2} \mathrm{~cm}^{2} / \mathrm{s}, c_{s}=4.9 \times 10^{5} \mathrm{~cm} / \mathrm{s}$ that are substituted in Eqs. 4 and 5, and then I and $S$ are calculated, and finally calculating Eq. 18, the result is approximately 0.01 . This is the worst case; when other values from Table 2 are substituted, the correction is even less. This small supplement does not affect the results. This demonstrates that the effect of water on the fluctuation frequency is negligible and, therefore, it can be determined by Eq. 
13.

\section{Membrane Fluctuations in a Pit Chamber Filled With Water}

When the membrane oscillates in water, water will flow through the membrane during its movement without any obstacle. In a pit chamber, when the membrane fluctuates from the equilibrium position, water due to its incompressibility, is forced to flow from the chamber through the pit aperture, to which the membrane moves, and flow from the other side of the membrane through the openings in the margo (Fig. 5).

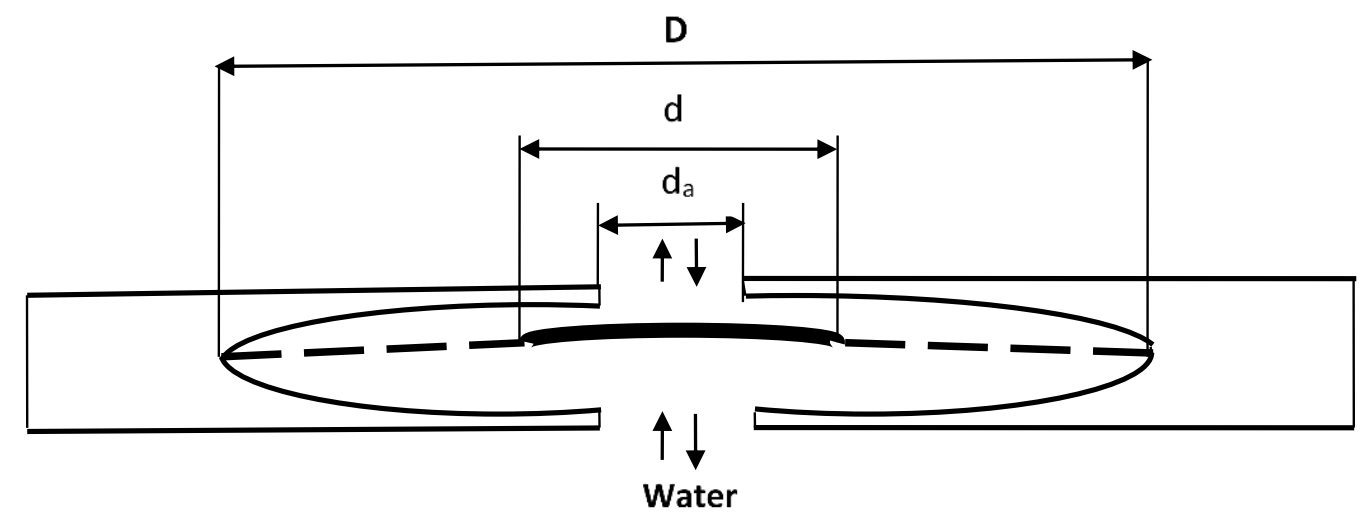

Fig. 5. Water movement through a pit membrane during fluctuation

When pumping water through both openings (i.e., pit aperture and margo), a differential pressure will occur relative to the two sides of the membrane, which will inhibit its movement. Comparing the free space in margo and pit apertures, the aperture area is $\pi d_{a}^{2} / 4$. The opening area in a real margo (assuming 80 strands), is determined by the difference in the margo area minus the area of the strands and is equal to $\frac{\pi\left(D^{2}-d^{2}\right)}{4}-80 h(D-d) / 2$. Substituting the data, the area of the openings in the margo exceeds the area of the aperture by 5 to 28 times depending on the parameters of the pit, and thus, the main flow of water will pass through the margo. The water velocity in the pit chamber $V_{1}$ is equal to the instantaneous membrane velocity $z_{t}{ }^{\prime}$ multiplied by the ratio of the torus area to the membrane area, which is $\delta=\left(\frac{d}{D}\right)^{2}$, i.e. $V_{1}=\delta z_{t}{ }^{\prime}$. A simplified assumption is that the entire membrane moves like a piston, where the torus pumps the water in contrast to the margo.

To find the resistance force of water flowing through the margo, we simulate its strands as cylinders with a diameter $h$. In this case, the Reynolds number is $R e \approx \frac{h \rho_{w} V_{1}}{\eta}=10$. For such a flow, the resistance force of one cylinder of length $\frac{D-d}{2}$ according to Ebert (1976) is shown below.

$$
F_{c}=10 \eta(D-d) \delta z_{t}{ }^{\prime}
$$

The thickness of margo strands is not in the formula. It is indirectly included in the coefficient, depending on the Reynolds number, for all 80 strands.

$$
F_{c}=80 \times 10 \eta(D-d) \delta z_{t}{ }^{\prime}
$$

Substituting the force (Eq. 20) referred to the diameter of the membrane into Eq. 9 produces Eq. 21 or 22. 


$$
\begin{aligned}
& E I z_{r}^{\prime \prime \prime \prime}+400\left(1-\frac{d}{D}\right) \eta \delta z_{t}{ }^{\prime}+\rho S z_{t}{ }^{\prime \prime}=0 \\
& \left(\frac{E I}{\rho S}\right) z_{r}^{\prime \prime \prime \prime}+\frac{400\left(1-\frac{d}{D}\right) \eta \delta z_{t}^{\prime}}{\rho S}+z_{t}^{\prime \prime}=0
\end{aligned}
$$

Substituting the values of the derivatives $z$ from Eq. 11,

$$
\frac{E I k^{4}}{\rho S}-\frac{i 400\left(1-\frac{d}{D}\right) \eta \delta \omega}{\rho S}-\omega^{2}=0
$$

Solving Eq. 23,

$$
\begin{aligned}
& \omega_{0}=\sqrt{ }\left(\frac{E I}{\rho S}\right) k^{4}-\left(200 \eta\left(1-\frac{d}{D}\right) \delta / \rho S\right)^{2} \\
& \gamma=-200 \eta\left(1-\frac{d}{D}\right) \delta / \rho S
\end{aligned}
$$

Recalling that $\omega=2 \pi f$, and without the last term in Eq. 24, Eq. 24 determines the oscillation frequency of a free membrane; see Eqs. 12 and 13. Accordingly, Eq. 24 is transformed, introducing $f_{c}$ - the oscillation frequency of the membrane in the chamber.

$$
f_{c}=\sqrt{f_{0}^{2}-\left(100 \eta\left(1-\frac{d}{D}\right) d^{2} / \pi \rho D^{2} S\right)^{2}}
$$

The ratios of membrane frequencies in the pit chamber calculated by Eq. 25 to the frequencies in free water $f_{c} / f_{0}$ are given in Table 4 .

Table 4. Ratios of Membrane Frequencies in Pit Chambers

\begin{tabular}{|c|c|c|c|}
\hline & $\begin{array}{c}\text { Minimum dimensions } \\
\text { of pit }\end{array}$ & $\begin{array}{c}\text { Maximum } \\
\text { dimensions of pit }\end{array}$ & $\begin{array}{c}\text { Average dimensions } \\
\text { of pit }\end{array}$ \\
\hline Earlywood & 0.94 & 0.99 & 0.98 \\
\hline Latewood & 0.99 & 0.96 & 0.99 \\
\hline
\end{tabular}

In earlywood, the decrease of frequency in the region of minimum size is due to the small thickness of the torus or the small mass making the membrane less inertial. In latewood, the decrease of frequency in the region of maximum sizes is due to the relative decrease in the size of margo, which complicates the flow of water through it. However, the effect of the pit chamber on the resonant frequency in all cases is not significant.

The influence of the pit chamber on fluctuations can have another effect, namely, to limit the fluctuation amplitude. The membrane should deviate to a distance sufficient to tear the margo strands, and the chamber walls should not interfere with this deviation, i.e., the oscillation amplitude of the membrane at which the strands will rupture must satisfy the condition $A_{c}<\frac{1}{2} H_{c}$. The maximum amplitude is apparently equal to the maximum deviation of the membrane, at which the strands tear due to their elongation. The maximum allowable elongation (Ebert 1976) is $\varepsilon \approx \frac{\sigma_{t}}{E} \approx 7 \times 10^{8} / 3.7 \times 10^{11} \approx 0.002$; consequently $A_{c}=0.1 D$ is calculated. Thus, the margo can be destroyed by the resonance frequency of the membrane for which the condition $0.1 D<\frac{1}{2} H_{c}$ or $\frac{D}{H_{c}}<5$ is fulfilled.

The necessary requirement $\frac{D}{H_{c}}<5$ is fulfilled for all cases, but considering the large spread in the strength limits of cellulose (Sjöström 1993; Monteiro et al. 2011), a problem 
can arise when trying to destroy margo strands of maximum sizes, especially in earlywood spruce tracheids.

\section{RESULTS AND DISCUSSION}

Theoretical calculations and their analysis showed the main resonant frequencies of bordered pit membranes for Norway spruce wood in the range of 3 to $11 \mathrm{MHz}$. The accuracy of the calculation results are determined by the accuracy of the physical characteristics of the torus and margo. Water filling the pit chamber does not have a significant effect on the main resonant frequencies of the membrane; with increasing temperature, this effect decreases even more due to a decrease in the water viscosity. The effect of pit apertures restricting the flow of water during the movement of the membrane does not affect the vibrations of the membrane inside the pit chamber due to the permeability of the margo to water.

The main limitation of the amplitude of membrane fluctuations inside the pit chamber can be the width of the chamber. To eliminate the effect of the membrane touching the walls of the chamber, it is possible to irradiate the membrane with twice the main resonant frequency. In this case, the shape of the membrane during deviations will be sinusoidal with zero deviation in the middle of the chamber, and not semi-sinusoidal with a maximum deviation in the middle of the chamber.

In order to initiate pit membrane resonance oscillations it is necessary to apply forces acting in opposite directions with a required frequency. Two possible methods are discussed. Water in wood contains ions with various mobility. In an electric field, the membrane will be charged by mobile ions and can move under alternating electric field in opposite directions. Alternating electric field applied perpendicular to membrane will initiate mechanical forces to move the membrane and destroy the margo. An ideal frequency for rupturing is the resonance frequency of the pit membranes (i.e., 3 to 11 $\mathrm{MHz}$ ). The desired range of frequencies of electromagnetic radiation can be achieved using a klystron.

Another method of pit membrane fluctuation is creating a pressure in the wood cell and transmitting the pressure to adjacent cells with a frequency within the membrane natural frequency range. To cause membrane oscillation, it is necessary to apply pressure alternatively from both sides of the pit membrane. Alternation of pressure application with required frequency can possibly be achieved by applying MW power for water evaporation in tracheids from alternate sides of the membrane. For example, a MW generator working at a frequency of $2.45 \mathrm{GHz}$ will emit enough energy for sufficient boiling of water in the cell lumen during a short period. Steam in the tracheid applies pressure to the membrane causing it to deflect to one side. After the energy comes to the next tracheid, the steam in the cell creates a pressure and deflects the membrane in reverse direction. In this way, the membrane activates into oscillation mode. As the next portion of energy comes in a defined time, it will repeat the membrane oscillation. Repetition of the oscillations with a defined frequency will destroy the membrane and open the pit. Microwaves can bring into wood the required membrane vibrations. Pulse energy application with define range of pulsation frequency can possibly provoke the process of membrane rupturing which leads to an increase of wood permeability without reduction in strength properties. 


\section{CONCLUSIONS}

1. The resonant frequencies of the membrane (torus and margo) of bordered pits of the sapwood of Norway spruce (and most likely other coniferous species) is found in the range of 3 to $11 \mathrm{MHz}$.

2. Water in the pit chamber does not have a noticeable effect on the resonant frequencies of the membrane. Margo is permeable for water and its influence on the water flow is low.

3. The main limitation of the amplitude of membrane fluctuations inside the pit chamber is the width of the chamber. The conclusion requires experimental confirmation.

4. Resonance frequency used for pit membrane disruption possibly requires less energy compared to other methods of increasing wood permeability. Pit membrane rupture would possibly not affect the wood mechanical properties.

5. Two methods for resonance frequency application for pit membrane destruction have been suggested, namely alternating electric field application and microwave energy pulsation.

\section{ACKNOWLEDGEMENTS}

The authors thank the financial support granted by the Swedish Research Council for Sustainable Development (FORMAS), to the project "Exploring microwave technology for energy efficient mechanical pulping and increased permeability of spruce wood"; grant number 2014-6383-27292-77.

\section{REFERENCES CITED}

Brändström, J. (2001). "Micro- and ultra-structural aspects of Norway spruce tracheids: A review," IAWA J. 22(49), 333-353. DOI: 10.1163/22941932-90000381

Ebert, H. (1976). Physikalisches Taschenbuch (Physical Handbook), Friedr. Vieweg \& Sohn Verlagsgesellschaft mbH, Braunschweig, Germany.

Monteiro, S. N., Lopes, F. P. D., Barbosa, A. P., Bevitori, A. B., Da Silva, I. L. A., and Da Costa, L. L. (2011). "Natural lignocellulosic fibers as engineering materials - An overview," Metall. Mater. Trans. A 42, Article ID 2963. DOI: 10.1007/s11661-0110789-6

Landau, L. D., and Lifshitz, E. M. (1986). Theory of Elasticity, Vol. 7 (3 ${ }^{\text {rd }}$ Ed.), Butterworth-Heinemann, Oxford, UK.

Mason, W. H. (1926). "Process and apparatus for disintegration of wood and the like," U.S. Patent 1578609.

Mayr, S., Rothart, B., and Dämon, B. (2003). "Hydraulic efficiency and safety of leader shoots and twigs in Norway spruce growing at the alpine timberline," J. Exp. Bot. 54(392), 2563-2568. DOI: 10.1093/jxb/erg272

Rosner, S., Klein, A., Müller, U., and Karlsson, B. (2007). "Hydraulic and mechanical properties of young Norway spruce clones related to growth and wood structure," Tree Physiol. 27(8), 1165-1178. DOI: 10.1093/treephys/27.8.1165 
Saren, M. P., Serimaa, R., Andersson, S., Paakkari, T., Saranpää, P., and Pesonen, E. (2001). "Structural variation of tracheids in Norway spruce (Picea abies [L.] Karst.)," J. Struct. Biol. 136(2), 101-109. DOI: 10.1006/jsbi.2001.4434

Siau, J. F. (1984). Transport Processes in Wood, Springer-Verlag, Berlin.

Sjöström, E. (1993). Wood Chemistry. Fundamentals and Applications, Academic Press, Cambridge, MA, USA.

Stamm, A. J. (1964). Wood and Cellulose Science, Ronald Press, New York.

Torgovnikov, G., and Vinden, P. (2009). "High intensity microwave wood modification for increasing permeability," Forest Prod. J. 59(4), 84-92.

Zimmermann, M. H. (1983). Xylem Structure and the Ascent of Sap ( $1^{\text {st }}$ Ed.), SpringerVerlag, Berlin.

Article submitted: December 3, 2020; Peer review completed: February 6, 2021; Revised version received and accepted; February 17, 2021; Published: February 19, 2021.

DOI: 10.15376/biores.16.2.2683-2695 